\title{
Blockchain in India
}

\author{
A.Sheela, M.SureshAnand, J.JeganAmarnath, S.Gurusubramani., D.Sathishkumar
}

\begin{abstract}
Blockchain has been the recent talk of the town in the sphere of digital technology which attempts to bring transparency in the wake of an Indian Digital Economy by inducing transparency and cracking on the rampant corruption in Public and Private Sectors by making use of Cryptographic Techniques to make the system hack-proof which is aimed at bringing an upheaval not only in the field of Finance but also other industries like Agriculture, Telecom, Mass Media and Public Sector Undertakings where coupled with contemporary technologies like Internet of Things, Blockchain can do wonders. This paper aims to give a brief view of about Blockchain, the basic ideas that revolve around it and how it can be implemented in a nation like India with over a billion population.
\end{abstract}

Index Terms: Blockchain, Blockchain in India, Technology in India, Cryptography

\section{INTRODUCTION}

Blockchain technology first broke the ice when the paper "Bitcoin: A Peer-to-Peer Electronic Cash System" [10] was revealed which laid out a mathematical foundation for implementing a Blockchain technology which laid a strong foundation for the rise of Cryptocurrencies like Bitcoin which saw a recent surge in upcoming years. The primary accomplishment of the Blockchain technology was that it saw the establishment of trust between two parties over a distributed system implementing a hack-proof and tamper-proof link between them with no central authority as we see in traditional databases [5]. Blockchain can be technically termed as a Data Structure just like the arrays/lists or Linked Lists and it has been seeing wide acceptance all over the world and also in India, with Bitcoin and Ethereum leading the race.

The potential of Bitcoin in India is unprecedented and if given a go-ahead it can help generate high-paying jobs among hundreds and thousands of low-skilled graduates in India. India has globally positioned itself as the Global IT Hub and in such a case the implementation of Blockchain technology in real-time myriad Indian Problems will be a blessing in disguise for Indian Government and Public where the need of Middlemen can be eliminated, the perception of data security can further be compounded and the speed of service can be increased along with a crackdown on Fraudulent Transactions which lead to tax evasions and a

Revised Manuscript Received on October 18, 2019.

A.Sheela, Department of Computer Science Engineering, Sri Sairam Engineering College, Chennai.

M.Suresh Anand, Department of Computer Science Engineering, Sri Sairam Engineering College, Chennai.

J.Jegan Amarnath, S.Gurusubramani ,D.Sathishkumar, Department of Computer Science Engineering, Sri Sairam Engineering College, Chennai. loss of thousands of crores to the Government of India and Tax Payers [3].

However, the Indian Government's response to the rise of Blockchain has been lamentably 'poor'. India's of Finance and Corporate Affairs Arun Jaitley in 2018 commented that the Blockchain is "Welcome" but Bitcoin is a "No" [8] further stating that cryptocurrencies are no recognised as legal tenders however the Blockchain technology is still being banked upon for further solving India's economic problems. Blockchain technology has got its own silver-lining in the cloud with the emergence of Bank-Chain, India's first Blockchain consortium and also the determination of Andhra Pradesh Government to implement Blockchain in managing land records which are undergoing a fraud crisis causing a loss of 1.3 percent of GDP Growth every year to the Indian economy [9].

\section{Concept of Blockchain}

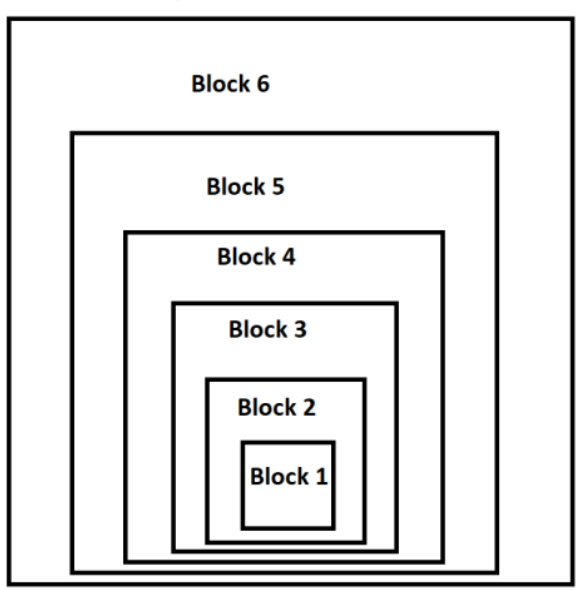

Fig: The concept of Blockchain can be easily explained by envisioning the concept of tamper-proof databases which is always put to public viewing and hence makes it virtually hack-proof and protected throughout its life

\section{EXPLAINING THE BLOCKCHAIN}

If we go into the technical terms, then Blockchain is a distributed ledger system, where for any new transaction to occur, a general consensus is needed by all the parties connected to the Blockchain network which is achieved by a process called "Mining" and the people involved in this process are called the "Miners". Blockchain induces decentralization in the network and all the databases are not stored on a single computer but on all the computers connected to the network. The blockchain is regarded as a One-Stop Solution to a wide array of problems that we face 


\section{Blockchain in India}

in a modern industry where multi-level transactions are required coupled with traceability and visibility to keep the transaction secure and build a common trust between parties [5][6]..

\section{Blockchain Architecture}

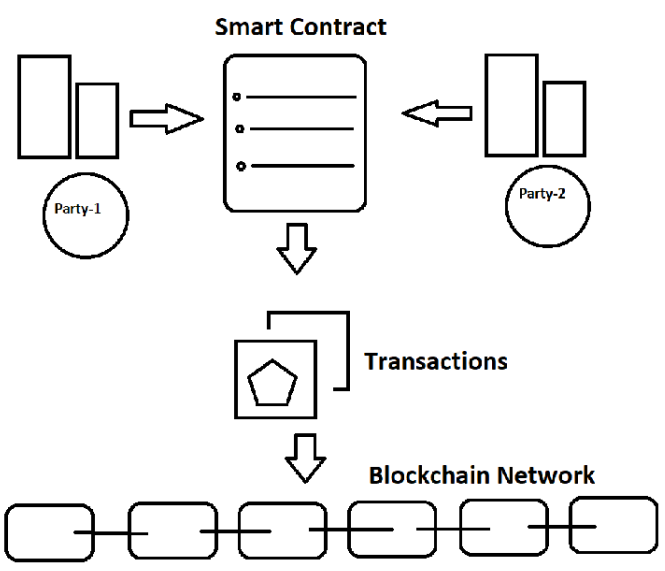

\section{Fig: Blockchain Network in Electronic Transactions}

By definition, Blockchain is a chain of blocks. When a blockchain network is established, all the computers connected to the network get a personal database where no updates or changes are possible without a consensus. To establish a consensus, between computers, miners are put at work who verify any new updates by solving an easy-to-verify but difficult to solve a cryptographic puzzle which is efficient on security terms but inefficient in computational power required. After submitting the proof-of-work a new block is proposed which is to be added. The particular block's footprint, which is to be added, is added to everyone's database by a cryptographic hashing technique which leads to alteration of each block in the network leading to the whole network to be updated. If two blocks, say $\mathrm{X}$ and $\mathrm{Y}$, are received at the same time with one part of the network receiving the Block $X$ while another part receiving Block $\mathrm{Y}$, then the most extended valid chain is recognized as the valid network while the other block is "orphaned" [12]. Blockchain, though riddled with disadvantages and limitations even now, carries a potential of paradigm shift, not only in the Finance Sector, but also other fields where the Internet of Value can play a big role in inducing better relationships between people on the Internet reinforced with all of the cryptography that goes behind the screens of our computers and one obvious thing: Consensus.

\section{BLOCKCHAIN IN INDIA}

India has been quite below the global standards when it came to adopting the Blockchain technology but there is a silver lining to the cloud. The Public Sector Undertakings and Government Owned Firms along with newly arisen startups are expected to bring the Blockchain revolution which would be the most combat-effective measure to fight the menace and unaccountability in a country like India. According to a Nasscom report [2], the Banking and Financial Sector is contemplating a Blockchain Revolution where 40 per cent of the initiatives are being executed by Government bodies with 92 per cent of the projects in the pilot phase and 8 per cent in the production phase. The report also suggested that the BFSI Sector are increasingly looking for Blockchain applications which can revolutionize the services provided by them and make them more efficient.

While BFSI has got a lion's share of the total number of the Blockchain initiatives at 60 per cent, other industries which are inducting Blockchain technology are Public Sector and Logistics at 15 per cent and 12 per cent respectively. Almost $50 \%$ of the Indian States have started adopting the Blockchain technology in regards to providing Digital Certificates, registering Land Records and getting Farm Insurance.

Some of the good examples of Blockchain Companies in India are PixelCrayons, which is an award-winning Blockchain-based Company specializing in Smart Contracts and Internet of Things, Sofocle Technologies, which specializes in-app wallet development and crypto coins, and Technoloader, which develops tools for Blockchain and Cryptocurrency. India is also a hub for startups and now many of the startups are also adopting Blockchain technology to provide its customers with a safe, secure and viable service in the face of 21 st Century security threats. Some of the startups include SOMISH [1], which specializes in Fund Transfers and Insurance and Ezyremit [1], which specializes in fintech, banking and payments.

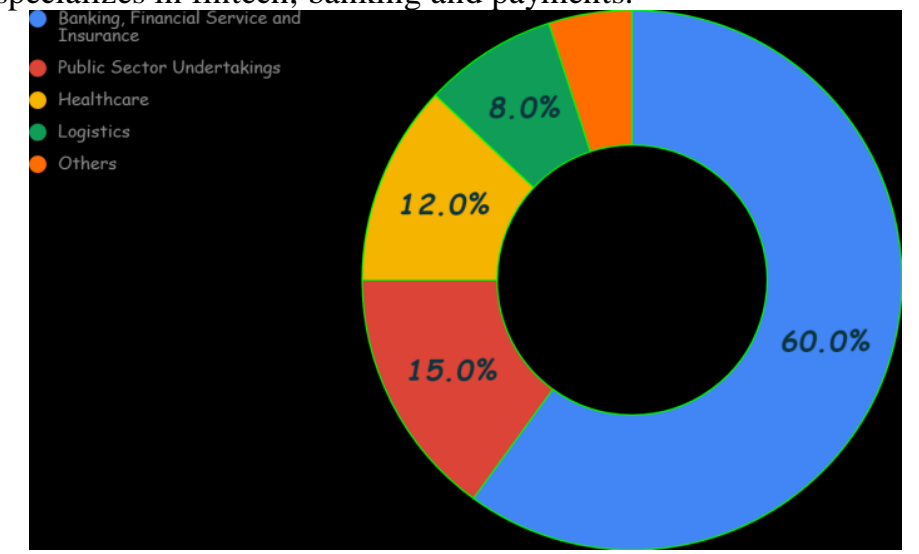

Fig: Adoption of Blockchain in India (Source: Avasant Analysis and Research)

Scope of Blockchain in India:

Here, we will discuss some of the prospects of Blockchain in India which goes beyond the Banking, Financial and Insurance Sector but also rope in other sectors like Healthcare, Defense, Travel, Public Sector Undertakings and Education among others. The future of Blockchain in India cannot be correctly predicted as of now due to a wide fog surrounding over its viability and whether it could serve the purpose even though it offers a wide range of solutions for a vast range of problems. Though many of the projects in India have not gone beyond the Proof-of-Work, we might see a rise of more and more Blockchain-related ventures and Startups in India with a new string of products which might soon find a way into our markets. Many investors and businessmen are scratching the surface and it will not take us long to adopt Blockchain, which coupled with Artificial Intelligence and Internet of Things, 
can multiply the end-dividends received from the Digital Revolution which is currently undergoing in India. The Blockchain can change the manner in which the organizations and services rendered by them are conveyed to the citizens, like the disposition of pilferages in the conveyance of such administrations where this is a critical issue, wipe out spillages in tax collections, along with maintenance of records and registers while also maintaining the supply chains of essential commodities.

This will allow us to explore further about how Blockchain can be beneficial in an Indian set up an environment which in particular is quite resistant to change:

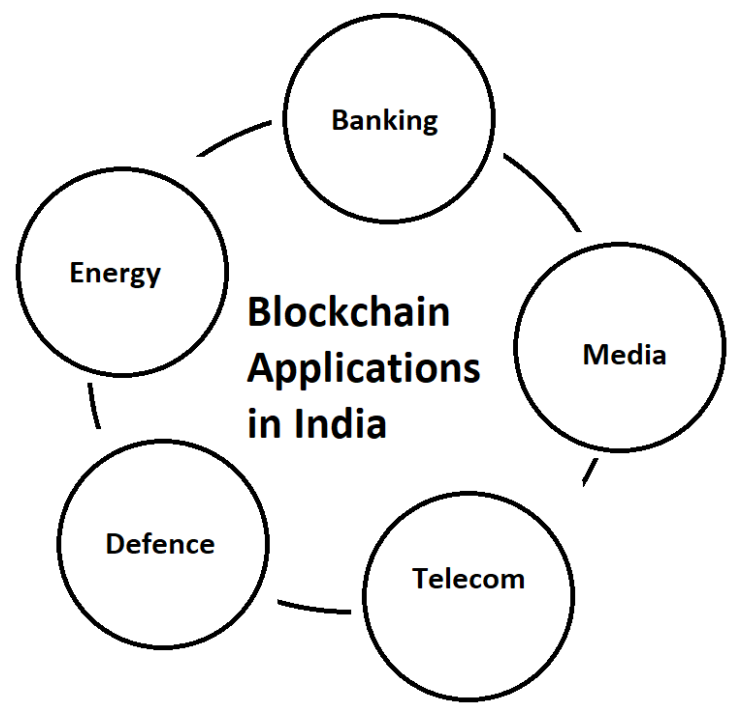

1. Banking: The first benefit that Blockchain could bring is in the Banking Sector [6]. Blockchain, in general, can revolutionize the Banking Sector in India which is undergoing a myriad of problems and issues currently which includes Bad Loans, Defaulters among others. Indian Banking Sector is now trying to establish a Blockchain network which would allow fast, easy to use and timely service to its customers putting an end to all frauds and loss of data as data would be decentralized and transparent allowing auditors to keep the transactions in check which might go beyond their rules and regulations. Blockchain did not take long to catch the attention of the Indian Banking System and in January 2019 a consortium of 11 Indian Banks which included ICICI Bank, Yes Bank and HDFC Bank to come other and launch a Blockchain Linked Funding Initiative for Small Scale and Medium Scale Enterprises. Banks can further explore the Blockchain in fields of clearing up the derivative controls, assets exchange, post-trade processing services and AML Registries. It will also reinforce the KYC or Identity Verification where thanks to the cryptographic coding behind the Blockchain technology, the identity of the person involved can be ascertained within a matter of time-saving a lot of time in tracking a transaction and the person(s) involved in it. Settle of Payments can also be done with the help of Blockchain which by reports given by Accenture would save the banks some \$10 Billion as it improves the efficiency of the whole mechanism. Currently, all major banks in India like Reserve Bank of India, ICICI Bank, Yes Bank and HDFC are testing the Blockchain technology and how can it be utilized to benefit Indian Customers.

2. Media: Blockchain can also solve many of the Media Problems in the field of Transaction associated with it. If we take for example the International Federation of the Phonographic Industry for 2014 report, that almost \$15 Billion were generated as globally generated revenue for sound recordings only a small amount of money reached the artist's beyond initial funding. Berklee Institute for Creative Entrepreneurship also commented that a major chunk of the revenue which ranges from 20-50 percent does not reach their rightful owners. Blockchain readily solves this problem with much-needed accountability especially in areas where micropayments and micro-transactions are involved. This can lead the customers to pay more for the service, greater efficiency and even greater accountability in regards to the copyrights behind the piece. Blockchain can also lead to a suppression of copyright infringements and plagiarisms which are the biggest bane in the Media Sector. Piracy has plagued the media sector since long were young millennials share content without attributing the original owners of their rightful share over the information. Blockchain can save the day over here if correctly utilized and prompted.

3. Telecom: Blockchain can also serve its purpose in the field of Telecom Industry coupled with the new buzz of the Tech World: Internet of Things (IoT). Telecommunications involve an extensive data exchange between vast arrays of networks which requires data security, inspection, introspection, integrity and above all fraud detection. Blockchain can secure all these operations with the vast arrays of advantages it provides. It simplifies a lot of processes which would otherwise take months to process and authenticate by means of Smart Contracts with a backend Blockchain Programmable Solution which can regulate all the stakeholders in the network and execute the contract with unprecedented accuracy and efficiency. It can also regulate KYC Applications allowing the Blockchain to store all its customer's detail in a decentralized way along with Audio, Video, Text and Image File Sharing between individuals on the network. The blockchain is also speculated to solve the collaboration problems between different parties on the network especially in the era of Internet and ever-rising connections like 5G Networks which would be leased by Network partners and also execute Supply Chain Management.

4. Defence: Blockchain can also address multiple of the issues in the Defense Industry in regards to Supply Chain Visibility, Supply Authentication, Deep Supply Chains, Product Certification and Quality Management. It can also provide the much needed military solutions for the Armed Forces with the ever-rising trend of Technology. Smart Drones have been in development in the past decade, which relays data recorded by it to a human operator and if destroyed, the native data would also be destroyed. Blockchain, coupled with Artificial Intelligence, can solve this problem as this could bring the Smart Drones on a Decentralized Network where all the drones share the Native Data with each other allowing the Artificial Intelligence to build up a real-time Battlespace visualization allowing it to function according to the perceived threat build-up and reacting to it. 


\section{Blockchain in India}

Blockchain can also power the Naval Assets which have a Central Command and Control Centre, which means a single point of failure. Once the Command Centre is taken down, the whole asset becomes incapable of combat though it might be equipped with a wide array of weaponry. Blockchain would decentralize the weapon control systems, allowing the assets to be controlled even from the Combat Capable Assets where different assets can coordinate with each other against the perceived threat by means of Cryptographic Communication where all nodes benefit from the same set of data. Blockchain implementation in Defence Headquarters can also keep a check on unauthorized access and network attacks by ensuring consensus-based access for any alteration or modification.

5. Energy: Blockchain is currently speculated to be the next opportunity for Energy Sector as it can revolutionize the power distribution by decentralizing yet keeping them integrated at the same time. Blockchain allows the Energy-based companies to increase their efficiency in transactions and executing contracts which is too compelling for huge entities to ignore, especially in an era where energy is becoming cheaper and cheaper. Smart Meters can be set up where energy consumption per capita can be checked in and updated into the database, without any outside interference, along with immediate reconciliation between supply and demand networks in the Energy Grid. Blockchain can also speed up Custom Clearance, Freight Traffic and immediate dispensation of services in real quick time. Besides big conglomerates controlling the supply of electricity, not only in India but also abroad, microgeneration of electricity has been a new trend where electricity is being generated at home or community level fostering the creation of an energy market where producers can share their power with a consumer at a different geographical location at a subtle location. Such contracts between two parties can be easily executed by the Blockchain network without any Third- Party or Red Tape involved.

\section{A.Problems with Blockchain in India:}

Though there is an increasing consciousness among Indians about the concept of Blockchain, there is still a dearth of lack of knowledge among mainstream Indians on how the Blockchain would benefit us and what would come out of it? Blockchain Technology is still in its infancy and many people associate the technology with the Bitcoin leading to a Catch 22 situation, which is flagged off by Reserve Bank of India as an illegal tender though it has not still be banned, which would have technically less to no effect. This has lead many of the Indians to see Bitcoin and subsequently the Blockchain as a "forbidden" technology though Blockchain can be utilized not only in the field of Cryptocurrencies but also other fields as has been discussed before.

Blockchain in India has also been predicted as a Costly Affair, as there has been no development of Infrastructure which can support Blockchain networks. There is also a lack of Blockchain Experts in India, mainly due to the lack of courses offered to Indian Graduates in their Bachelors and Masters which can be a budding stage for them to learn about Blockchain and about its implementation in the real world. In Cryptocurrencies, the majority of the maintenance is done by the Miners, who mine the blocks and are rewarded against the Proof-of-Work done by them. Apart from the cryptocurrencies, it still has not been made clear who would maintain the whole Blockchain network in the absence of Miners who would be needed to validate the peer-to-peer process.

Many of the students who gain the required resources and specialization in Blockchain shift abroad due to the presence of better opportunities. Many of the available Blockchain courses available to Indian Students are simply not enough to nurture developers, required for setting an indigenous setup for Blockchain, in quality or quantity.

Blockchain is today's date has reached a hype cycle of what the Internet was when it had its first commercial use. Blockchain today has reached the maximum of its hype cycle and many people are taking in unrealistic expectations and its predictability as a mainstream technology is difficult to ascertain especially with the challenges surrounding it. Though the digitization movement has largely been successful throughout India, many people are still alien to the basic concepts of Internet and Digital Transactions which makes the adoption of Blockchain quite difficult en masse. A FactorDaily investigation has also revealed that many of the Government Bodies have not moved past the Proof-of-Concept and the complete realization of the Blockchain is still a distant dream. Many of the Blockchain networks are still at their infancy in India and it is still a challenge to migrate a traditional database system onto the Blockchain Network.

Blockchain still suffers from the traditional problem of nascency where UX and Scalability [18] have been the areas still not completely stressed upon along with the regulations under which any Blockchain network would work. One of the reasons why Blockchain might "fail" in a country like India, is the underlying politics behind it. Blockchain can be the next big thing in Voting Technology where votes are cast in Electronic Voting Machines (EVMs) and Ballot Papers and then evaluated. Adoption of the Blockchain in Voting Mechanism can completely put all the data of an individual at risk along with their political affiliation which is quite risky in a nation like India where everyone's vote is kept anonymous. Introduction of Blockchain, though would bring a paradigm shift, would also be likely to meet stiff resistance from political parties who traditionally resisted against such measures in the past also.

Blockchain would bring a paradigm shift from centralized, closed-door discussions to an open, participatory discussion where everyone can look through the thought process behind important decision making, which will push the value back to the consumer not to the producer, as is done traditionally. Though it promises a wide array of solutions to vast problems which yet remain solved, our primary priority should be to overcome the limitations posed by the network and rope in required resources to mark a shift from the old hierarchical structures where trust is laid upon the technology, not the institutions. 


\section{CONCLUSION}

In this paper, we have discussed what Blockchain is and how can this be beneficial in a national set up like India and obviously the limitations posed by such a bleeding-edge technology. Blockchain as of today is a ubiquitous hot-topic and it serves its purpose of "disintermediation" which shifts the "trust" from the institution to the technology and establishes a consensus between parties while involved in any transaction. The future of Blockchain in India would see a further rise of innovation and methods to combat native problems with Blockchain networks like the introduction of proof-of-stake, proof-of-ownership, proof-of-location to be able to achieve faster and much more energy-efficient consensus between parties including the introduction of graphs to link the blocks instead of the traditionally linearly-lined blocks. Moderated Blockchains are also the talk of the town where the Blockchain can be moderated by a central authority whom we can trust like a Federated Blockchain where disruptiveness can be reduced while keeping the exorbitant transaction costs in check quite effectively. Though it goes against the basic definition of Blockchain, it might be argued that Blockchain which is still in its infancy and it cannot be argued that how it would be adopted in the coming future. The paper has therein served its purpose of giving a comprehensive approach on how Blockchain can serve in various applications and frameworks across India along with a setup to introduce Blockchain to someone who has not encountered the term before, with detailed dissemination of merits and demerits..

\section{REFERENCES}

1. S. Khatwani, "11 Blockchain Startups From India - CoinSutra Picks", CoinSutra - Bitcoin Community, 2019. [Online]. Available: https://coinsutra.com/indian-blockchain-s tartups/. [Accessed: 14- Mar2019].

2. "Public Sector \& BFSI Driving Blockchain Adoption in India: NASSCOM Report", Crypto-News India, 2019. [Online]. Available: https://www.crypto-news.in/news/public-

sector-bfsi-driving-blockchain-adoption-india-nasscom-report/. [Accessed: 14- Mar- 2019].

3. N. Tanvi Ratna, "Opinion | The importance of blockchain for India", https://www.livemint.com, 2019. [Online]. Avail- able: https://www.livemint.com/Opinion/wNYSOWfLeUIDPc

FddJL84K/The-importance-of-blockchain-for-India.html. [Ac- cessed: 14- Mar- 2019].

4. "Here's how blockchain can return confidence to the Indian food industry", The Economic Times, 2019. [Online]. Available: https://m.economictimes.com/small-biz/security

-tech/technology/heres-how-blockchain-can-return-confide nce-to-the-indian-food-industry/articleshow/68020591.cms. [Accessed: 14- Mar- 2019].

5. "The great chain of being sure about things", The Economist, 2019. [Online].

Available:https://www.economist.com/briefing/2015/10/31/the-great-ch ain-of-being-sure-about- things. [Accessed: 14- Mar- 2019].

6. "Blockchain: Future of financial and cyber security - IEEE Conference Publication", Ieeexplore.ieee.org, 2019. [On- line]. Available: https://ieeexplore.ieee.org/document/7918009 /. [Accessed: 14- Mar2019].

7. "Blockchain: Challenges and applications - IEEE Con- ference Publication", Ieeexplore.ieee.org, 2019. [Online]. Available: https://ieeexplore.iee.org/document/8343163. [Ac- cessed: 14- Mar2019].

8. "A Vehement 'No' to Cryptocurrencies but Blockchain is 'Welcome', Arun Jaitley Says", News18, 2019. [Online]. Available: https://www.news18.com/news/business/a-veheme

nt-no-to-cryptocurrencies-but-blockchain-is-welcome-arun-jai tley-says-1648003.html. [Accessed: 14- Mar- 2019].

9. Sinha, "How Andhra Pradesh Is Emerging As India's Blockchain Hub", Analytics India Magazine, 2019. [Online]. Available: https://www.analyticsindiamag.com/how-andhra-pr

adesh-is-emerging-as-indias-blockchain-hub/. [Accessed: 14-Mar2019].

10. S. Nakamoto, "Bitcoin: A Peer-to-Peer Electronic Cash System", Bitcoin.org, 2019. [Online]. Available: https://bitcoi n.org/bitcoin.pdf. [Accessed: 14- Mar- 2019].

11. "Blockchain Explained: Ultimate Guide on How Blockchain Works", BitDegree Tutorials, 2019. [Online]. Available: https://www.bitdegree.org/tutorials/blockchain-expl ained/. [Accessed: 14- Mar- 2019].

12. P. Mathew, Manorama Year Book 2019 (English). Malayala Manorama (5 December 2018), 2019, pp. 73-78.

13. "Moving From Bleeding Edge To Cutting Edge: How The Blockchain Will Reshape Finance", Forbes.com, 2019. [Online]. Available: https://www.forbes.com/sites/mraneri/201

6/04/14/moving-from-bleeding-edge-to-cutting-edge-how-the

-blockchain-will-reshape-finance/\#3f7600a62370. [Accessed: 14- Mar2019].

14. T. Research, "Blockchain Technology Market to Gain Revenue Worth US $\$ 20$ bn by 2024 - TMR", Prnewswire.com, 2019. [Online]. Available: https://www.prnewswire.com/new

s-releases/blockchain-technology-market-to-gain-revenue-wo rth-us20-bn-by-2024---tmr-686428221.html. [Accessed: 14-Mar2019].

15. "Using Blockchain Technology to Boost Cyber Security", Steelkiwi.com, 2019. [Online]. Available: https://st eelkiwi.com/blog/using-blockchain-technology-to-boost-cyber security/. [Accessed: 14- Mar- 2019].

16. "The Meaning of Decentralization", Medium, 2019. [Online]. Available:

https://medium.com/@VitalikButerin/the-meaning-of-decentralization-a 0c92b76a274. [Accessed: 14-Mar- 2019].

17. "One Bitcoin Transaction Consumes As Much Energy As Your House Uses in a Week", Motherboard, 2019. [Online]. Available: https://motherboard.vice.com/en_us/articl e/ywbbpm/bitcoin-mining-electricity-consumption-ethereum-e nergy-climate-change. [Accessed: 14- Mar- 2019].

18. C.Blenkinsop, "Blockchain's Scaling Problem, Explained",

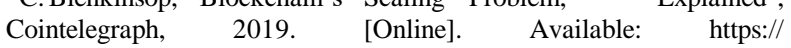
cointelegraph.com/explained/blockchains-scaling-problem-ex plained. [Accessed: 14- Mar- 2019].

\section{AUTHORS PROFILE}

Working as Associate professor in Sri Sai Ram Engineering College for the past 17 years and completed MCA, M.Tech, M.Phil, handled many subjects

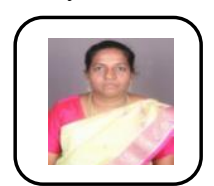
few are Data Base Management System, Relational Data Base Management System, Computer Graphics, Computer Networks, Computer Architecture, Python Programming .The area of interest is Data Base Management System, Computer Networks. Organized and participated in various national levels Technical Symposium, FDPs, Staff Development programme, National Level seminars and workshops. Presented many papers in both national, international conferences and reputed International Journals. Having Life Membership in ISTE professional bodies and published paper in SCOPUS Journal. Has been completed three NTPEL online exams with Elite grade. Acted as a Resource Person for various programmers in distance education. Has been question paper setter for various colleges and university. Had been Certified Trainer in C Programming by ICT Academy.

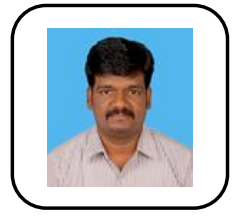

M.SureshAnand, is working as an Associate professor/CSE in Sri Sairam engineering college, Chennai. He had published more than 50 papers in reputed journals and conferences. He is having 15 years of experience in teaching. His areas of interest are Image Processing, Computer Vision, Machine Learning, Human Computer Interaction and Deep Learning. He also member in IAENG \& IACSIT. 


\section{Blockchain in India}

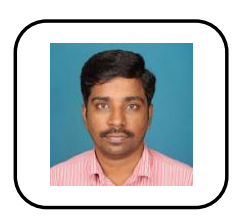

J.JeganAmarnath, is working as an Associate professor/CSE in Sri Sairam engineering college, Chennai. He had published papers in reputed journals and conferences. He is having 20 years of experience in teaching. He is a member in IAENG \& IACSIT. His areas of interest are Data mining, Soft computing, Artificial intelligence, Machine Learning, Human Computer Interaction and Deep Learning..

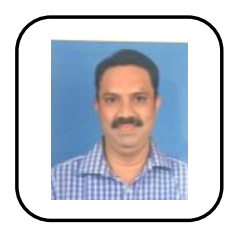

S.Gurusubramani, is working as an Associate professor/CSE in Sri Sairam engineering college, Chennai. He is having 20 years of experience in teaching. His areas of interest are e-learning, Computer networks, Cloud computing and Distributed systems. He also member in IAENG.

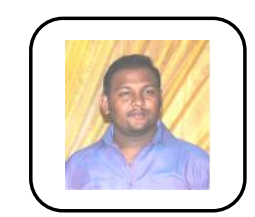

D.Satish Kumar, completed Bachelor degree (B.Tech) in Information Technology from anna University and Masters in Information Technology from Sathyabama University. Working as a Assistant Professor in Sri Sairam Engineering College, Chennai. Area of Research is networking and wireless communction. Life member of CSI, ISTE and IAENG. 